\title{
Sudden Death in Multiple Sclerosis Associated with Sun Exposure: a Report of Two Cases
}

\author{
Simon P. Avis and William E.M. Pryse-Phillips
}

\begin{abstract}
Background: Two cases of sudden unexpected deaths in patients with multiple sclerosis were investigated by the Office of The Chief Forensic Pathologist. Method: Case studies. Results: Marked similarities of the deaths, including circumstances, scene examination, and autopsy findings including a complete drug screen were recorded. Conclusions: Exposure to high ambient temperature may pose a danger to patients with multiple sclerosis. Mechanisms of death and the potential dangers to patients with clinically widespread disease are discussed.
\end{abstract}

\begin{abstract}
RÉSUMÉ: Mort subite associée à une exposition solaire dans la sclérose en plaques: à propos de deux cas. Introduction: Le bureau du médecin légiste en chef a investigué deux cas de mort subite chez des patients atteints de sclérose en plaques. Méthode: Étude de cas. Résultats: Des ressemblances importantes entre les deux décès ont été notées quant aux circonstances, à l'examen des lieux et aux résultats de l'autopsie, qui incluait un examen toxicologique complet. Conclusions: L'exposition à des températures ambiantes élevées peut être dangereuse pour les patients atteints de sclérose en plaques. Nous discutons des mécanismes du décès et des dangers potentiels pour les patients qui ont une maladie disséminée cliniquement.
\end{abstract}

Can. J. Neurol. Sci. 1995; 22: 305-307

Multiple sclerosis (MS) is a demyelinating disease of unknown etiology, characterized by a relapsing and remitting course or steady progression over several years. While occasionally patients die as a result of complications of MS, most die with the disease rather than from it. Sudden death is unusual, but two such cases associated with sun exposure are presented below.

\section{Case Histories}

\section{Patient I}

A 28-year-old woman complained in 1983 of bouts of tremor, occasional vertigo, nausea and vomiting and imbalance. She had been investigated by an endocrinologist for hyperthyroidism on account of apparent left eye proptosis but this diagnosis was not confirmed. In 1985 she complained of occasional vertigo still and of weakness, numbness and clumsiness of the legs and, one month prior to referral, numbness of the left hand. Other symptoms experienced included numbness in the tips of the fingers in her right hand, worsening of memory, tremor in both hands, imbalance and increasing numbness in the left foot. On examination she was found to have right temporal pallor with horizontal jerk nystagmus on right and left lateral gaze, vertical nystagmus on upgaze and a bilateral pyramidal syndrome due to a lesion above the $\mathrm{C} 5$ spinal level but below the pons. Visual and auditory evoked responses were grossly abnormal; CSF showed CSF protein $0.61 \mathrm{~g} / \mathrm{l}$ with positive oligoclonal banding.

Three years later, her clinical signs were much as before but now with the addition of obvious cerebellar abnormalities in both arms and vermis ataxia. She was treated with Amantidine and a tricyclic drug as an outpatient. In August 1986 her problems included weakness in the legs, imbalance, frequency, and urgency of micturition and dizziness; there was pallor of both optic disks and prominent up-beating nystagmus in both eyes. Because of the worsening of symptoms she was readmitted and treated with cyclophosphamide $1 \mathrm{gm}$ IV $\times 5$. Zantac and acetaminophen were also prescribed for related problems. She was later discharged to homecare. One year later, her physical signs due to MS had deteriorated further despite these therapies and she was admitted for rehabilitation, but elected not to complete the program offered and discharged herself against advice. Over the subsequent few years she continued to deteriorate slowly to the extent of requiring substantial personal care. By November 1989 she rated 7 on the Kurtzke scale, deficits mainly being of ocular movement, with substantial pyramidal, cerebellar, posterior column and some spinothalamic involvement, bilateral optic atrophy and internuclear ophthalmoplegia. She was not offered further treatment and remained at home dependent upon her family for care, although able to ambulate with assistance when not in a wheelchair.

On the day of her death (during the summer of 1990) she had been sunbathing on her back porch clad in a bikini. She had been last seen alive by a relative at $1120 \mathrm{hrs}$. At $1320 \mathrm{hrs}$ a neighbour noticed that she had not moved for a period of time and decided to see if she was alright. Upon checking he found the subject lying prone with no apparent signs of life, and summoned medical help. The deceased was pronounced dead on arrival at the local hospital at $1538 \mathrm{hrs}$. At the time of admission to the emergency department body core temperature was recorded as $42^{\circ} \mathrm{C}$. The temperature recorded on the deceased's porch at the time of her death was $48^{\circ} \mathrm{C}$.

From the Department of Pathology and Department of Neurology, Memorial University of Newfoundland, St. John's, Newfoundland.

RECEIVED MARCH 21, 1995. ACCEPTED IN FINAL FORM MAY 31, 1995.

Reprint requests to: Simon P. Avis, M.D., Department of Pathology. Health Sciences Centre, St. John's, Newfoundland. Canada A I B 3 V6 
An autopsy was performed the following day and revealed erythema and blistering of the skin. Gross and microscopic evaluation of the thoracic organs revealed pulmonary edema and focal alveolar hemorrhage. The cardiovascular system and abdominal organs were non-contributory. Examination of the central nervous system revealed multiple plaques both in the cortical hemispheres and brain stem, consistent with MS. Microscopic examination confirmed the presence of demyelinating plaques throughout the brain. Body fluid analysis for alcohol was negative while a drug screen was positive for carbamazepine within the therapeutic range, and for trace amounts of ibuprofen and amantadine. The cause of death was recorded as hyperthermia in a 34-year-old female with MS.

\section{Patient 2}

In 1977, this 27-year-old woman complained of numbness and tingling in the right arm, followed by paraesthesia and weakness in both legs and fluctuating vision in the left eye. She was found to have a markedly diminished colour field to red in the left eye; temporal pallor bilaterally, fine vertical jerk nystagmus on upward gaze; and slight alteration of sensation in the right hand; there was evidence of both pyramidal and cerebellar involvement in the legs. CSF total protein was $77 \mathrm{mg} / \mathrm{dl}$, (IgG $24 \mathrm{mg} \%$ ). A diagnosis of MS was made.

Over the course of the next 12 years, she was admitted for high dose IV methyl prednisolone pulse therapy on a number of occasions, usually due to increasing cerebellar or pyramidal problems, but over these years some evidence of posterior column involvement was also found. In 1992, pathological emotionality and internuclear ophthalmoplegia were noted; at this time she was having great difficulty in continuing to work, and was awarded permanent disability.

During her seventeen years of slowly progressive MS a CT scan of the head was performed on one occasion and was considered normal; no MRI was performed, the diagnostic category being "clinical definite". Even in 1979, her symptoms had been markedly worsened by heat, and this continued over the years leading up to her death. She was last seen in December 1993, at which time a recent course of IV pulsed therapy had improved her walking to some extent, although examination still revealed horizontal jerk nystagmus to right and left, mild euphoria, vermis ataxia, and bilateral posterior column and pyramidal signs and affecting the legs more than the arms.

The patient had last been seen alive at $0830 \mathrm{hrs}$ on the day of her death by an acquaintance. At approximately $1700 \mathrm{hrs}$ the same day her neighbours noted her sitting on a lawn chair on her porch, became concerned, checked on her and found her dead. The police examination at the scene showed that there was no evidence of any disturbance, the subject being seated on a lawn chair with a cup of tea to one side. There was no evidence of any attempt to extricate herself from the chair. The high temperature recorded by the local weather office that day was $27.2^{\circ} \mathrm{C}$ during 14.1 hours of bright sunshine. The ambient temperature at the scene and the body core temperature were not measured.

Autopsy was undertaken on the following day and revealed erythema and blistering of the skin in a distribution consistent with the exposed body areas. Examination of the cardiovascular system showed a heart of normal size with no evidence of fibrosis. The left anterior descending artery showed a maximum of $50 \%$ atherosclerotic narrowing, the remaining coronary arteries being free of atherosclerosis. The lungs and abdominal organs were unremarkable. On sectioning, the brain revealed numerous demyelinating plaques involving the cerebral hemispheres and brain stem, including the floor of the medulla, all of which were confirmed microscopically. Body fluid analyses for alcohol and drugs were negative.

\section{Discussion}

The effect of increased body temperature on demyelinated nerve fibres in MS is well known. From a clinical perspective this may result in an exacerbation of preexisting symptoms or the emergence of new symptoms in a patient exposed to an increase in body core temperature (Uhtoff's sign).

The basis of Uhtoff's sign is considered to be the reduction in conduction velocity of myelinated fibres in the CNS as a result of an increased core body temperature. Conversion from an intermittent to complete conduction block has been shown to occur in individual nerve fibres with an increase in temperature of only $0.5^{\circ} \mathrm{C} .^{\prime}$ Electrophysiological studies suggest that demyelination exposes axonal potassium channels that decrease action potential duration and amplitude, hindering propagation of the action potential. ${ }^{2}$

Clinically, it is well-known that symptoms of MS may appear or worsen as a result of thermal stress ${ }^{3.4}$ although this opinion has been disputed. ${ }^{5}$ The same phenomenon has been demonstrated to occur also in the peripheral nervous system, conduction speeds in demyelinated fibres falling as temperature rises. ${ }^{6}$ The drug 4-aminopyridine has been assessed for its effect in reversing the increased conduction block within demyelinated fibres. Visual, motor and oculomotor functions or other prospectively-defined neurological deficits were improved in a substantial majority of temperature-sensitive MS patients ${ }^{2,7.8}$ and certain objective tests results were also improved. ${ }^{9,10}$ Kurtzke EDSS scores improved in some but not in other studies as a result of 4aminopyridine treatment.

These two cases show that heat exposure is potentially lethal in patients with MS. We are aware of numerous anecdotal accounts of serious but temporary disablement as well as two other published reports of death in MS patients following heat exposure. One of these involved an individual who became incapacitated in a hot tub and subsequently died as a result of third degree burns, ${ }^{11}$ while the second case a female who was sunbathing became incapacitated and subsequently died, presumably as a result of hyperthermia - circumstances similar to those reported here. ${ }^{12}$ In this case the victim had had a previous episode of heat-induced incapacitation while sunbathing and had been cautioned not to sunbathe alone. Unfortunately no autopsy nor drug screen to exclude other possible causes of death were performed by a medical examiner. Furthermore, although hyperthermia was cited as the proximate cause of death, the core body temperature was not stated. Establishing hyperthermia as a cause of death is difficult at autopsy unless a core temperature is recorded during life. The autopsy findings are non-specific and consist of evidence of circulatory failure such as pulmonary edema, which is present in many other causes of death.

How fast does incapacitation occur with exposure to heat? The on-the-scene examination of our two cases suggests that it may occur so quickly that the subject cannot extricate him or herself from danger. In neither of our cases was there any evidence of efforts to escape. This contrasts to some reports on non-fatal outcomes of heat-induced morbidity in MS patients in whom the subjects were able to summon help when they became aware of their incapacitation. ${ }^{11.12}$ An alternate explanation may be that instead of incapacitation with resulting hyperthermia, death occurs rapidly from brainstem malfunction as a consequence of heat-induced conduction block or due to edema or other malfunction involving the brainstem centres controlling cardiac, respiratory activity, or blood pressure. In each of our cases, the victim had extensive brainstem involvement. If such were to be correct, the general autopsy findings would be nonspecific. Furthermore while changes consistent with heat exposure, namely erythema and blistering, were present in both cases, both are known to occur as postmortem artifacts in a body exposed to heat. ${ }^{13}$ It is also accepted that the core temperature of a dead body will increase or decrease until it reaches ambient temperature. For this reason, the recorded core temperature of our first case may be misleading if death had been sudden and the body had remained exposed to $48^{\circ} \mathrm{C}$ ambient temperatures. 
Regardless of the mechanism of death, the above examples reaffirm the extreme potential danger of high ambient temperatures to individuals with clinically widespread lesions of MS. Clinicians who are involved in the management of such patients should educate them about the dangers of such exposure.

\section{REFERENCES}

1. Rasminsky $M$. The effects of temperature on conduction in demyelinated single nerve fibers. Arch Neurol 1973; 28: 287292.

2. Bever CT, Jr. The current status of studies of aminopyridines in patients with multiple sclerosis. Ann Neurol 1994; 36: S118S121.

3. O'Reilly MA, O'Reilly PM. Temporal influences on relapses of multiple sclerosis. Eur Neurol 1991; 31: 391-395.

4. Tan CT. The hot bath test among Malaysian multiple sclerosis patients. Med J Malaysia 1994; 49: 68-73.

5. Ponichtera-Mulcare JA. Exercise and multiple sclerosis. Med Sci Sports Exerc 1993: 25: 451-466.
6. Chaudhry V, Crawford TO, DeRossett SE. Thermal sensitivity in demyelinating neuropathy. Muscle Nerve 1993; 16: 301-306.

7. Davis FA, Stefoski D, Rush J. Orally administered 4-aminopyridine improves clinical signs in multiple sclerosis. Ann Neurol 1990; 27: 186-192.

8. van Diemen HA, Polman CH, van Dongen TM, et al. The effect of 4-aminopyridine on clinical signs in multiple sclerosis. Ann Neurol 1992; 32: 123-130.

9. Accornero N, De Vito G, Rotunno. A, et al. Critical fusion frequency in MS during mild induced hyperthermia. Acta Neurol Scand 1989; 79: 510-514.

10. Bever CT Jr, Young D, Anderson PA, et al. The effects of 4aminopyridine in multiple sclerosis patients: results of a randomized, placebo-controlled, double-blind, concentration controlled crossover trial. Neurology 1994; 44: 1054-1059.

11. Waxman SG, Geschwind N. Major morbidity related to hyperthermia in multiple sclerosis. Ann Neurol 1983; 13:348.

12. Harbison JW, Calabrese VP, Edlich RF. A fatal case of sun exposure in a multiple sclerosis patient. J Emerg Med 1989: 7: 465467.

13. Knight B. Forensic Pathology. New York: Oxford University Press, 1991: 287-288. 